\title{
Perbandingan Biaya Material dengan Memodifikasi Struktur Bangunan Menggunakan Beton Ringan pada Proyek Gedung Asrama Berlantai 5 LPMP Sumatera Barat
}

\author{
Kharista Hadya Nata Putra, Tri Joko Wahyu Adi \\ Departemen Teknik Sipil, Fakultas Teknik Sipil, Lingkungan dan Kebumian, \\ Institut Teknologi Sepuluh Nopember Surabaya \\ e-mail: trijokowahyuadi@gmail.com
}

\begin{abstract}
Abstrak-Material inovatif adalah material material konstruksi yang dapat dijadikan pilihan atau pertimbangan lain dalam penggunaanya pada konstruksi dan telah memenuhi fungsi dari penggunaanya pada konstruksi. Dampak dari penggunaan material-material yang inovatif adalah metode pelaksanaan lebih mudah, beban yang diterima struktur dari material bangunan juga lebih ringan, waktu pelaksanaan dan beberapa kelebihan lainnya.

Penelitian ini bertujuan untuk membandingkan biaya material pada modifikasi struktur bangunan yang menggunakan material yang inovatif yang ringan yaitu pelat lantai pracetak ringan dan bata ringan dengan struktur eksisting bangunan yang menggunakan pelat lantai beton biasa dan bata merah. Dengan modifikasi struktur diharapkan dimensi struktur akan berubah jika menggunakan material yang inovatif dan membandingkan perubahannya terhadap biaya material terpasang. Ada 3 skenario perbandingan yang dilakukan pada penelitian ini, skenario pertama adalah struktur eksisting yaitu struktur yang pelat lantai dan dindingnya sama dengan bangunan aslinya yaitu pelat lantai konvensional dan dinding bata merah, skenario kedua adalah struktur modifikasi 1 yaitu struktur bangunan dengan penggantian pelat lantai konvensional dengan pelat lantai pracetak ringan dari beton aerasi dan dinding tetap menggunakan bata merah, dan scenario ketiga adalah struktur modifikasi 2 yaitu struktur bangunan dengan penggantian pelat lantai konvensional dengan pelat lantai pracetak ringan dari beton aerasi dan dinding bata merah dengan dinding bata ringan dari beton aerasi. Pada penelitian ini, proyek yang digunakan sebagai studi kasus adalah proyek Gedung Asrama Berlantai 5 LPMP Sumatera Barat. Lokasi proyek berada di kawasan kampus Universitas Negeri Padang, kota Padang.

Dari hasil analisa yang telah dilakukan penurunan biaya antara struktur eksisting dengan struktur modifikasi 1, adalah sebesar $12.70 \%$ yaitu $\operatorname{Rp} 925,923,369.61$ dan penurunan biaya antara struktur eksisting dengan struktur modifikasi 2 adalah sebesar $18.36 \%$ yaitu $R p$ 1,338,149,665.30. Alternatif penggunaan pelat lantai pracetak ringan dan bata ringan sangat mempengaruhi struktur terutama pada beban yang diterima struktur yang secara langsung mempengaruhi volume sebuah struktur dan dapat direkomendasikan saat perencanaan sebuah gedung.
\end{abstract}

Kata kunci-Material Inovatif, Beton Aerasi.

\section{PENDAHULUAN}

$\mathrm{P}$ EMBANGUNAN infrastruktur di Indonesia pada beberapa tahun ini sangat digencarkan oleh pemerintah untuk kemudahan akses, tempat tinggal dan untuk kebutuhan masyarakat lainnya. Pada kota-kota besar sempitnya lahan yang ada harus dimanfaatkan dengan sebaik - baiknya untuk memenuhi kebutuhan masyarakat seperti tempat tinggal permanen bagi yang menetap, ataupun tempat tinggal sementara bagi para pendatang dengan urusannya yang bermacam-macam. Cara yang paling efektif dan efisien untuk permasalahan tersebut adalah membangun bangunan bertingkat yang juga secara langsung membutuhkan teknologi yang bisa mencapai tujuan dengan efisien dan efektif .

Perkembangan teknologi dalam pembangunan bangunan bertingkat dapat mempermudah untuk tercapainya pemanfaatan lahan yang terbatas dengan sebaik-baiknya. Perkembangan teknologi ini bisa berupa material-material inovatif, hingga metode pelaksanaan yang lebih efektif dan efisien.

Beberapa contoh material-material inovatif yang digunakan untuk bangunan diantaranya adalah timbercrete yaitu beton yang menggunakan serbuk kayu sebagai agregat halus dan menghasilkan beton yang ringan, ashcrete yaitu beton yang menggunakan abu terbang sebagai pengganti semen yang berasal dari hasil pembakaran batu bara, hempcrete yaitu beton yang terbuat dari serat tanaman hemp yang dicampur dengan kapur sehingga menghasilkan bahan mirip beton namun kuat dan ringan, dan aeration lightweight concrete atau beton aerasi yaitu beton yang ditambahkan gelembung udara ke dalam mortar akan mengurangi berat beton yang dihasilkan secara drastis dan masih banyak material-material inovatif lainya yang juga berasal dari proses daur ulang dan bersifat ramah lingkungan.

Dampak dari penggunaan material material inovatif ini pada bangunan bertingkat secara umum adalah dapat mengurangi jumlah sampah, sifatnnya berkelanjutan karena berasal dari tumbuhan, ramah lingkungan. Dari segi konstruksi, dampak 
dari penggunaan material-material yang inovatif adalah metode pelaksanaan lebih mudah, beban yang diterima struktur dari material bangunan juga lebih ringan, waktu pelaksanaan dan beberapa kelebihan lainnya.

Penelitian ini bertujuan untuk membandingkan biaya material pada modifikasi struktur bangunan yang menggunakan material yang inovatif yang ringan yaitu pelat lantai pracetak ringan dan bata ringan dengan struktur eksisting bangunan yang menggunakan pelat lantai beton biasa dan bata merah, dengan harapan dimensi struktur akan berubah jika menggunakan material yang inovatif dan membandingkan perubahannya terhadap biaya material terpasang.

Pada penelitian ini, proyek yang digunakan sebagai studi kasus adalah proyek Gedung Asrama Berlantai 5 LPMP Sumatera Barat. Lokasi proyek berada di kawasan kampus Universitas Negeri Padang, kota Padang. Fungsi bangunannya adalah sebagai gedung asrama dan ruang kuliah yang diperuntukkan bagi mahasiswa yang berdomisili di luar kota Padang. Diharapkan pada proyek ini, dengan menggunakan material inovatif yang ringan akan dapat mengurangi biaya material dari struktur bangunan tersebut.

\section{URAIAN PENELITIAN}

Material inovatif adalah material material konstruksi yang dapat dijadikan pilihan atau pertimbangan dalam penggunaanya pada konstruksi dan telah memenuhi fungsi dari penggunaanya pada konstruksi. Material-material tersebut didapat dari hasil penelitian yang lama dan harus memenuhi fungsi dari material yang digantikan dengan beberapa keunggulan lainnya kemudian melakukan pengujian sebelum boleh digunakan pada konstruksi. Penggunaan material-material inovatif ini pada konstruksi juga mengubah metode pelaksanaan konstruksi tersebut. Pemilihan jenis material yang terpilih didasari oleh pemroduksian massalnya dan berat jenis material itu sendiri yang lebih ringan dari material yang digunakan pada eksisting beton. Material inovatif terpilih adalah beton ringan aerasi.

Menurut Prabowo, Beton ringan AAC adalah beton yang pembuatannya menggunakan mesin Autoclaved Aerated Concrete $(A A C)$ dimana didalam campuran beton tersebut telah terdapat lapisan pembesian 2 lapis yang telah didesain mampu menahan beban kerja[1].

Menurut Limanto, dkk, karakteristik beton ringan adalah sebagai berikut:

1) presisi, karena dibuat oleh pabrik dan menggunakan mesin, maka ukuran dan bentuk dari beton ringan ini lebih presisi dari pada bata konvensional yang dibuat dengan menggunakan tenaga manusia,

2) sudut siku, sudut yang dimiliki beton ringan benar-benar tegak lurus membentuk 900,

3) permukaan halus dan pori pori lebih rapat, permukaan pada beton ringan umumnya rata dan halus, serta memiliki pori yang lebih rapat, hal ini yang menyebabkan beton ringan lebih kedap air,
4) ringan dan kuat, beton ringan sesuai namanya memiliki berat yang lebih ringan dari bata konvensional, hampir 1/3 berat dari bata konvensional. Tetapi walaupun memiliki berat yang ringan beton ringan tetap kuat[2].

\section{A. Konsep Desain Struktur}

Konsep desain struktur yang dilakukan adalah sebagai berikut:

1) Struktur Eksisting

Pada struktur eksisting ini, dilakukan perencanaan Gedung Asrama Berlantai 5 LPMP Sumatera Barat dilakukan sesuai dengan material eksisting yang dipakai yaitu material beton bertulang biasa dan dinding menggunakan bata merah tanpa ada perubahan.

2) Struktur Modifikasi 1

Pada struktur modifikasi 1 ini, dilakukan perencanaan Gedung Asrama Berlantai 5 LPMP Sumatera Barat dilakukan dengan material beton bertulang biasa pelat lantai kantilever, balok, dan kolom dan dinding menggunakan bata merah. Sedangkan pelat lantai menggunakan pelat lantai pracetak ringan dengan bahan beton aerasi sehingga mempengaruhi dimensi dan biaya dari struktur tersebut.

3) Struktur Modifikasi 2

Pada struktur modifikasi 2 ini, dilakukan perencanaan Gedung Asrama Berlantai 5 LPMP Sumatera Barat dilakukan dengan material beton bertulang biasa pelat lantai kantilever, balok, dan kolom. Sedangkan pelat lantai menggunakan pelat lantai pracetak ringan dengan bahan beton aerasi dan dinding menggunakan bata ringan beton aerasi sehingga mempengaruhi dimensi dan biaya dari struktur tersebut.

a) Pelat Lantai Pracetak Ringan

Berikut adalah data-data perencanaan pelat lantai pracetak ringan:

1) Kuat Tekan $\quad=6.5 \mathrm{~N} / \mathrm{mm}^{2}$

2) Berat Jenis Nominal $=650 \mathrm{Kg} / \mathrm{m}^{3}$

3) Berat Perencanaan $=750 \mathrm{Kg} / \mathrm{m}^{3}$

4) Beban Imposed $\quad=405 \mathrm{Kg} / \mathrm{m}^{2}$

Modulus elastisitas beton aerasi adalah[3]:

$$
\mathrm{E}=1550 \times \mathrm{S}^{0.7}
$$

Dengan:

$\mathrm{E}=$ Modulus Elastisitas Beton Aerasi

$\mathrm{S}=$ Kuat Tekan Beton $\left(\mathrm{Kg} / \mathrm{m}^{2}\right)$

b) Bata Ringan

Berikut adalah data-data perencanaan bata ringan :

1) Kuat Tekan = $=4 \mathrm{~N} / \mathrm{mm}^{2}$

2) Berat Jenis Nominal $\quad=495 \mathrm{Kg} / \mathrm{m}^{3}$

3) Berat Perencanaan $\quad=595 \mathrm{Kg} / \mathrm{m}^{3}$

4) Daya Hantar Panas $=0.195 \mathrm{w} / \mathrm{mK}$

5) Ketahanan Api (SNI 1741 2008) = 3 jam

6) Isulansi Suara (ASTM E90) - STC $=41 \mathrm{~dB}$

c) Biaya Material Terpasang

Perhitungan volume material terpasang pada struktur berdasarkan hasil dari perencanaan struktur tersebut dan biaya material terpasang pada struktur adalah berdasarkan HSPK 2018 kota Surabaya. 
Pada Gambar 1 dibawah ini ditampilkan HSPK 2018 kota Surabaya.

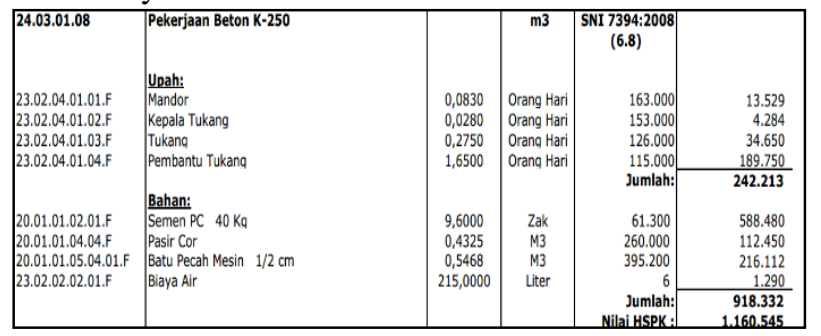

Gambar 1. HSPK Kota Surabaya 2018.

\section{HASIL PERENCANAAN DAN PERHITUNGAN BIAYA STRUKTUR}

\section{A. Struktur Eksisting}

Hasil perhitungan desain, volume, dan biaya struktur eksisting dapat dilihat pada Tabel 1.

Setelah dilakukan perhitungan volume dan biaya struktur eksisting, dibawah ini ditampilkan pada Tabel 2 rekapitulasi hasil perhitungan volume dan biaya struktur eksisting sebagai berikut:

Tabel 1.

Hasil perhitungan struktur eksisting

\begin{tabular}{|c|c|c|c|c|c|}
\hline \multirow{2}{*}{\multicolumn{2}{|c|}{ Uraian }} & \multicolumn{4}{|c|}{ Struktur Eksisting } \\
\hline & & \multicolumn{2}{|c|}{ Volume } & \multicolumn{2}{|c|}{ Biaya (Rp) } \\
\hline \multirow{15}{*}{ Beton } & Pelat Lantai & 392.63 & $\mathrm{~m} 3$ & $\mathrm{Rp}$ & $387,241,051.16$ \\
\hline & Balok Induk 1 & 205.14 & $\mathrm{~m} 3$ & $\mathrm{Rp}$ & $202,327,568.49$ \\
\hline & Balok Induk 2 & 88.2 & $\mathrm{~m} 3$ & $\mathrm{Rp}$ & $86,990,539.86$ \\
\hline & Balok Anak 1 & 41.21 & $\mathrm{~m} 3$ & $\mathrm{Rp}$ & $40,648,844.78$ \\
\hline & Balok Anak 2 & 8.64 & $\mathrm{~m} 3$ & $\mathrm{Rp}$ & $8,521,522.27$ \\
\hline & Sloof & 18.69 & $\mathrm{~m} 3$ & $\mathrm{Rp}$ & $18,433,709.64$ \\
\hline & Poer K1 & 139.97 & $\mathrm{~m} 3$ & $\mathrm{Rp}$ & $138,048,660.81$ \\
\hline & Poer K2-1K & 12.96 & $\mathrm{~m} 3$ & $\mathrm{Rp}$ & $12,782,283.41$ \\
\hline & Poer K2-2K & 38.88 & $\mathrm{~m} 3$ & $\mathrm{Rp}$ & $38,346,850.22$ \\
\hline & Poer K3 & 3.24 & $\mathrm{~m} 3$ & $\mathrm{Rp}$ & $3,195,570.85$ \\
\hline & Kolom K1-12 & 74.88 & $\mathrm{~m} 3$ & $\mathrm{Rp}$ & $73,853,193.02$ \\
\hline & Kolom K1-34 & 58.37 & $\mathrm{~m} 3$ & $\mathrm{Rp}$ & $57,567,617.13$ \\
\hline & Kolom K1-5 & 25.54 & $\mathrm{~m} 3$ & $\mathrm{Rp}$ & $25,185,832.49$ \\
\hline & Kolom K2 & 166.9 & $\mathrm{~m} 3$ & $\mathrm{Rp}$ & $164,607,405.22$ \\
\hline & Kolom K3 & 4.18 & $\mathrm{~m} 3$ & $\mathrm{Rp}$ & $4,118,735.76$ \\
\hline \multicolumn{2}{|l|}{ Tiang Pancang } & 3592 & $\mathrm{~m}$ & $\mathrm{Rp}$ & $481,285,075.60$ \\
\hline \multirow{15}{*}{ Tulangan } & Pelat Lantai & 81176.36 & $\mathrm{Kg}$ & $\mathrm{Rp}$ & $1,160,992,360.51$ \\
\hline & Balok Induk 1 & 40143 & $\mathrm{Kg}$ & $\mathrm{Rp}$ & $574,129,152.44$ \\
\hline & Balok Induk 2 & 18356.9 & $\mathrm{Kg}$ & $\mathrm{Rp}$ & $262,542,238.91$ \\
\hline & Balok Anak 1 & 8679.66 & $\mathrm{Kg}$ & $\mathrm{Rp}$ & $124,137,334.94$ \\
\hline & Balok Anak 2 & 1253.3 & $\mathrm{Kg}$ & $\mathrm{Rp}$ & $17,924,786.87$ \\
\hline & Sloof & 1920.51 & $\mathrm{Kg}$ & $\mathrm{Rp}$ & $27,467,390.34$ \\
\hline & Poer K1 & 30452.02 & $\mathrm{Kg}$ & $\mathrm{Rp}$ & $435,527,879.26$ \\
\hline & Poer K2-1K & 4402.08 & $\mathrm{Kg}$ & $\mathrm{Rp}$ & $62,958,962.14$ \\
\hline & Poer K2-2K & 12847.41 & $\mathrm{Kg}$ & $\mathrm{Rp}$ & $183,744,937.40$ \\
\hline & Poer K3 & 747.24 & $\mathrm{Kg}$ & $\mathrm{Rp}$ & $10,687,151.56$ \\
\hline & Kolom K1-12 & 10268.75 & $\mathrm{Kg}$ & $\mathrm{Rp}$ & $146,864,639.75$ \\
\hline & Kolom K1-34 & 8128.43 & $\mathrm{Kg}$ & $\mathrm{Rp}$ & $116,253,669.27$ \\
\hline & Kolom K1-5 & 3618.65 & $\mathrm{Kg}$ & $\mathrm{Rp}$ & $51,754,357.75$ \\
\hline & Kolom K2 & 35774.36 & $\mathrm{Kg}$ & $\mathrm{Rp}$ & $511,648,525.66$ \\
\hline & Kolom K3 & 1538.13 & $\mathrm{Kg}$ & $\mathrm{Rp}$ & $21,998,433.23$ \\
\hline \multirow{5}{*}{ Bekisting } & Balok & 2973.01 & $\mathrm{~m} 2$ & $\mathrm{Rp}$ & $676,020,773.12$ \\
\hline & Kolom & 2052.32 & $\mathrm{~m} 2$ & $\mathrm{Rp}$ & $442,012,570.89$ \\
\hline & Pelat Lantai & 3141 & $\mathrm{~m} 2$ & $\mathrm{Rp}$ & $676,483,923.15$ \\
\hline & Sloof & 74.76 & $\mathrm{~m} 2$ & $\mathrm{Rp}$ & $10,054,121.03$ \\
\hline & Poer & 241.92 & $\mathrm{~m} 2$ & $\mathrm{Rp}$ & $32,534,683.78$ \\
\hline \multicolumn{2}{|c|}{ Total Keseluruhan Biaya Struktur Eksisting } & & & $\mathrm{Rp}$ & $7,288,892,352.72$ \\
\hline
\end{tabular}

Tabel 2.

Rekapitulasi hasil perhitungan pada struktur eksisting

\begin{tabular}{ccccr}
\hline \hline & Volume & Satuan & & \multicolumn{1}{c}{ Biaya } \\
\hline Beton & 1279.41 & $\mathrm{~m}^{3}$ & $\mathrm{Rp}$ & $1,261,869,385.13$ \\
Tulangan & 259306.80 & $\mathrm{Kg}$ & $\mathrm{Rp}$ & $3,708,631,820.03$ \\
Tiang Pancang & 3592 & $\mathrm{~m}$ & $\mathrm{Rp}$ & $481,285,075.60$ \\
Bekisting & 8483.01 & $\mathrm{~m}^{2}$ & $\mathrm{Rp}$ & $1,837,106,071.97$ \\
\hline \hline
\end{tabular}

\section{B. Struktur Modifikasi 1}

Hasil perhitungan desain, volume, dan biaya struktur modifikasi 1 dapat dilihat pada Tabel 3 .

Setelah dilakukan perhitungan volume dan biaya struktur modifikasi 1, dibawah ini ditampilkan pada Tabel 4 rekapitulasi hasil perhitungan volume dan biaya struktur modifikasi 1 . 
JURNAL TEKNIK ITS Vol. 7, No. 2, (2018) ISSN: 2337-3539 (2301-9271 Print)

Tabel 3.

Hasil Perhitungan Struktur Modifikasi 1

\begin{tabular}{|c|c|c|c|c|c|}
\hline & \multirow{2}{*}{ Uraian } & \multicolumn{4}{|c|}{ Struktur Modifikasi 1} \\
\hline & & \multicolumn{2}{|c|}{ Volume } & \multicolumn{2}{|r|}{ Biaya } \\
\hline \multicolumn{2}{|c|}{ Pelat Lantai Pracetak } & 2120 & bh & $\mathrm{Rp}$ & $756,840,000.00$ \\
\hline & Pelat Lantai & 24.74 & $\mathrm{~m} 3$ & $\mathrm{Rp}$ & $24,399,958.77$ \\
\hline & Balok Induk 1 & 175.83 & $\mathrm{~m} 3$ & $\mathrm{Rp}$ & $173,423,630.14$ \\
\hline & Balok Induk 2 & 70.56 & $\mathrm{~m} 3$ & $\mathrm{Rp}$ & $69,592,431.89$ \\
\hline & Balok Anak 1 & 36.06 & $\mathrm{~m} 3$ & $\mathrm{Rp}$ & $35,567,739.18$ \\
\hline & Balok Anak 2 & 5.4 & $\mathrm{~m} 3$ & $\mathrm{Rp}$ & $5,325,951.42$ \\
\hline & Sloof & 23.28 & $\mathrm{~m} 3$ & $\mathrm{Rp}$ & $22,960,768.34$ \\
\hline & Poer K1 & 69.98 & $\mathrm{~m} 3$ & $\mathrm{Rp}$ & $69,024,330.40$ \\
\hline \multirow[t]{8}{*}{ Beton } & Poer $\mathrm{K} 2-1 \mathrm{~K}$ & 15.55 & $\mathrm{~m} 3$ & $\mathrm{Rp}$ & $15,338,740.09$ \\
\hline & Poer K2-2K & 46.66 & $\mathrm{~m} 3$ & $\mathrm{Rp}$ & $46,016,220.27$ \\
\hline & Poer K3 & 2.59 & m3 & $\mathrm{Rp}$ & $2,556,456.68$ \\
\hline & Kolom K1-12 & 39.94 & $\mathrm{~m} 3$ & $\mathrm{Rp}$ & $39,388,369.61$ \\
\hline & Kolom K1-345 & 43.78 & $\mathrm{~m} 3$ & $\mathrm{Rp}$ & $43,175,712.84$ \\
\hline & Kolom K2-12 & 31.68 & $\mathrm{~m} 3$ & $\mathrm{Rp}$ & $31,245,581.66$ \\
\hline & Kolom K2-345 & 344.74 & $\mathrm{~m} 3$ & $\mathrm{Rp}$ & $340,008,738.65$ \\
\hline & Kolom K3 & 5.8 & $\mathrm{~m} 3$ & $\mathrm{Rp}$ & $5,720,466.34$ \\
\hline \multicolumn{2}{|c|}{ Tiang pancang } & 2422 & $\mathrm{~m}$ & $\mathrm{Rp}$ & $324,519,057.10$ \\
\hline & Pelat Lantai Pracetak & 9627.04 & $\mathrm{Kg}$ & $\mathrm{Rp}$ & $137,686,856.54$ \\
\hline & Pelat Lantai & 1790.07 & $\mathrm{Kg}$ & $\mathrm{Rp}$ & $25,601,724.07$ \\
\hline & Balok Induk 1 & 35958.6 & $\mathrm{Kg}$ & $\mathrm{Rp}$ & $514,283,544.30$ \\
\hline & Balok Induk 2 & 18074.42 & $\mathrm{Kg}$ & $\mathrm{Rp}$ & $258,502,091.60$ \\
\hline & Balok Anak 1 & 8816.48 & $\mathrm{Kg}$ & $\mathrm{Rp}$ & $126,094,190.65$ \\
\hline & Balok Anak 2 & 707.05 & $\mathrm{Kg}$ & $\mathrm{Rp}$ & $10,112,232.18$ \\
\hline & Sloof & 3093.27 & $\mathrm{Kg}$ & $\mathrm{Rp}$ & $44,240,285.68$ \\
\hline & Poer K1 & 16935.05 & $\mathrm{Kg}$ & $\mathrm{Rp}$ & $242,206,830.81$ \\
\hline \multirow[t]{10}{*}{ Tulangan } & Poer K2-1K & 3763.35 & $\mathrm{Kg}$ & $\mathrm{Rp}$ & $53,823,740.18$ \\
\hline & Poer K2-2K & 17608.31 & $\mathrm{Kg}$ & $\mathrm{Rp}$ & $251,835,848.55$ \\
\hline & Poer K3 & 710.25 & $\mathrm{Kg}$ & $\mathrm{Rp}$ & $10,158,084.65$ \\
\hline & Kolom K1-12 & 8310.38 & $\mathrm{Kg}$ & $\mathrm{Rp}$ & $118,855,862.99$ \\
\hline & Kolom K1-345 & 11199.48 & $\mathrm{Kg}$ & $\mathrm{Rp}$ & $160,176,107.08$ \\
\hline & Kolom K2-12 & 14143.8 & $\mathrm{Kg}$ & $\mathrm{Rp}$ & $202,286,107.53$ \\
\hline & Kolom K2-345 & 53930.19 & $\mathrm{Kg}$ & $\mathrm{Rp}$ & $771,314,971.34$ \\
\hline & Kolom K3 & 1111.21 & $\mathrm{Kg}$ & $\mathrm{Rp}$ & $15,892,682.00$ \\
\hline & Balok & 2597.22 & $\mathrm{~m} 2$ & $\mathrm{Rp}$ & $590,572,278.94$ \\
\hline & Kolom & 3426.88 & $\mathrm{~m} 2$ & $\mathrm{Rp}$ & $738,054,513.39$ \\
\hline \multirow{3}{*}{ Bekisting } & Pelat Lantai & 206.16 & $\mathrm{~m} 2$ & $\mathrm{Rp}$ & $44,401,122.44$ \\
\hline & Sloof & 93.12 & $\mathrm{~m} 2$ & $\mathrm{Rp}$ & $12,523,271.14$ \\
\hline & Poer & 217.44 & $\mathrm{~m} 2$ & $\mathrm{Rp}$ & $29,242,483.63$ \\
\hline \multicolumn{3}{|c|}{ Total Keseluruhan Biaya Struktur Modifikasi 1} & & $\mathrm{Rp}$ & $6,362,968,983.11$ \\
\hline
\end{tabular}

Tabel 4.

Rekapitulasi Hasil Perhitungan pada Struktur Modifikasi 1

\begin{tabular}{|c|c|c|c|}
\hline & Volume & Satuan & Biaya \\
\hline Beton & 980.5 & $\mathrm{~m}^{3}$ & $\begin{array}{ll}\text { Rp } & 923,745,096.30\end{array}$ \\
\hline Tulangan & 198302.95 & $\mathrm{Kg}$ & Rp $2,943,071,160.16$ \\
\hline Tiang Pancang & 2422 & $\mathrm{~m}$ & $\operatorname{Rp} \quad 324,519,057.10$ \\
\hline $\begin{array}{c}\text { Pelat lantai } \\
\text { pracetak ringan }\end{array}$ & 2199 & $\mathrm{~m}^{2}$ & $756,840,000.00$ \\
\hline Bekisting & 6540.82 & & Rp 1,414,793,669.54 \\
\hline
\end{tabular}

\section{Struktur Modifikasi 2}

Hasil perhitungan desain, volume, dan biaya struktur modifikasi 2 dapat dilihat pada Tabel 5.

Setelah dilakukan perhitungan volume dan biaya struktur modifikasi 2, dibawah ini ditampilkan pada Tabel 6 rekapitulasi hasil perhitungan volume dan biaya struktur modifikasi 2 . 
JURNAL TEKNIK ITS Vol. 7, No. 2, (2018) ISSN: 2337-3539 (2301-9271 Print)

Tabel 5.

Hasil perhitungan struktur modifikasi 2

\begin{tabular}{|c|c|c|c|c|c|}
\hline \multirow{2}{*}{\multicolumn{2}{|c|}{ Uraian }} & \multicolumn{4}{|c|}{ SStruktur Modifikasi 2} \\
\hline & & \multicolumn{2}{|c|}{ Volume } & \multicolumn{2}{|r|}{ Biaya } \\
\hline \multicolumn{2}{|c|}{ Pelat Lantai Pracetak } & 2120 & bh & $\mathrm{Rp}$ & $756,840,000.00$ \\
\hline \multirow{15}{*}{ Beton } & Pelat Lantai & 24.74 & $\mathrm{~m} 3$ & $\mathrm{Rp}$ & $24,399,958.77$ \\
\hline & Balok Induk 1 & 175.83 & $\mathrm{~m} 3$ & $\mathrm{Rp}$ & $173,423,630.14$ \\
\hline & Balok Induk 2 & 79.38 & m3 & $\mathrm{Rp}$ & $78,291,485.87$ \\
\hline & Balok Anak 1 & 36.06 & $\mathrm{~m} 3$ & $\mathrm{Rp}$ & $35,567,739.18$ \\
\hline & Balok Anak 2 & 5.4 & $\mathrm{~m} 3$ & $\mathrm{Rp}$ & $5,325,951.42$ \\
\hline & Sloof & 23.28 & $\mathrm{~m} 3$ & $\mathrm{Rp}$ & $22,960,768.34$ \\
\hline & Poer K1 & 69.98 & $\mathrm{~m} 3$ & $\mathrm{Rp}$ & $69,024,330.40$ \\
\hline & Poer K2-1K & 12.96 & $\mathrm{~m} 3$ & $\mathrm{Rp}$ & $12,782,283.41$ \\
\hline & Poer K2-2K & 38.88 & $\mathrm{~m} 3$ & $\mathrm{Rp}$ & $38,346,850.22$ \\
\hline & Poer K3 & 1.94 & $\mathrm{~m} 3$ & $\mathrm{Rp}$ & $1,917,342.51$ \\
\hline & Kolom K1-12 & 39.94 & $\mathrm{~m} 3$ & $\mathrm{Rp}$ & $39,388,369.61$ \\
\hline & Kolom K1-345 & 43.78 & $\mathrm{~m} 3$ & $\mathrm{Rp}$ & $43,175,712.84$ \\
\hline & Kolom K2-12 & 22 & $\mathrm{~m} 3$ & $\mathrm{Rp}$ & $21,698,320.60$ \\
\hline & Kolom K2-345 & 239.4 & $\mathrm{~m} 3$ & $\mathrm{Rp}$ & $236,117,179.62$ \\
\hline & Kolom K3 & 5.8 & $\mathrm{~m} 3$ & $\mathrm{Rp}$ & $5,720,466.34$ \\
\hline \multicolumn{2}{|c|}{ Tiang Pancang } & 2334 & $\mathrm{~m}$ & $\mathrm{Rp}$ & $312,728,108.70$ \\
\hline \multirow{16}{*}{ Tulangan } & Pelat Lantai Pracetak & 9627.04 & $\mathrm{Kg}$ & $\mathrm{Rp}$ & $137,686,856.54$ \\
\hline & Pelat Lantai & 1790.07 & $\mathrm{Kg}$ & $\mathrm{Rp}$ & $25,601,724.07$ \\
\hline & Balok Induk 1 & 35958.6 & $\mathrm{Kg}$ & $\mathrm{Rp}$ & $514,283,544.30$ \\
\hline & Balok Induk 2 & 18333.36 & $\mathrm{Kg}$ & $\mathrm{Rp}$ & $262,205,559.96$ \\
\hline & Balok Anak 1 & 8816.48 & $\mathrm{Kg}$ & $\mathrm{Rp}$ & $126,094,190.65$ \\
\hline & Balok Anak 2 & 1181.78 & $\mathrm{Kg}$ & $\mathrm{Rp}$ & $16,901,924.18$ \\
\hline & Sloof & 3093.27 & $\mathrm{Kg}$ & $\mathrm{Rp}$ & $44,240,285.68$ \\
\hline & Poer K1 & 16938.26 & $\mathrm{Kg}$ & $\mathrm{Rp}$ & $242,252,687.77$ \\
\hline & Poer K2-1K & 2908.89 & $\mathrm{Kg}$ & $\mathrm{Rp}$ & $41,603,274.09$ \\
\hline & Poer K2-2K & 13977.36 & $\mathrm{Kg}$ & $\mathrm{Rp}$ & $199,905,633.22$ \\
\hline & Poer K3 & 449.27 & $\mathrm{Kg}$ & $\mathrm{Rp}$ & $6,425,478.29$ \\
\hline & Kolom K1-12 & 6386.78 & $\mathrm{Kg}$ & $\mathrm{Rp}$ & $91,344,383.74$ \\
\hline & Kolom K1-345 & 8388.07 & $\mathrm{Kg}$ & $\mathrm{Rp}$ & $119,967,022.01$ \\
\hline & Kolom K2-12 & 13828.55 & $\mathrm{Kg}$ & $\mathrm{Rp}$ & $197,777,272.36$ \\
\hline & Kolom K2-345 & 48180.45 & $\mathrm{Kg}$ & $\mathrm{Rp}$ & $689,081,590.86$ \\
\hline & Kolom K3 & 991.53 & $\mathrm{Kg}$ & $\mathrm{Rp}$ & $14,181,008.55$ \\
\hline \multirow{5}{*}{ Bekisting } & Balok & 2656.02 & $\mathrm{~m} 2$ & $\mathrm{Rp}$ & $603,942,578.68$ \\
\hline & Kolom & 3044.48 & $\mathrm{~m} 2$ & $\mathrm{Rp}$ & $655,696,203.23$ \\
\hline & Pelat Lantai & 206.16 & $\mathrm{~m} 2$ & $\mathrm{Rp}$ & $44,401,122.44$ \\
\hline & Sloof & 93.12 & $\mathrm{~m} 2$ & $\mathrm{Rp}$ & $12,523,271.14$ \\
\hline & Poer & 200.16 & $\mathrm{~m} 2$ & $\mathrm{Rp}$ & $26,918,577.65$ \\
\hline \multicolumn{2}{|c|}{ Total Keseluruhan Biaya Struktur Modifikasi 2} & & & $\mathrm{Rp}$ & $5,950,742,687.42$ \\
\hline
\end{tabular}

Tabel 6.

Rekapitulasi Hasil Perhitungan pada Struktur Modifikasi 2

\begin{tabular}{ccclcr}
\hline \hline & Volume & Satuan & & \multicolumn{2}{c}{ Biaya } \\
\hline Beton & 864.3 & $\mathrm{~m}^{3}$ & & $\mathrm{Rp}$ & $808,140,389.30$ \\
Tulangan & 187439.9 & $\mathrm{Kg}$ & & $\mathrm{Rp}$ & $2,729,552,436.28$ \\
Tiang Pancang & 2334 & $\mathrm{~m}$ & & $\mathrm{Rp}$ & $312,728,108.70$ \\
Pelat lantai & 2199 & $\mathrm{bh}$ & & $\mathrm{Rp}$ & $756,840,000.00$ \\
pracetak ringan & & & & & \\
Bekisting & 6199.94 & $\mathrm{~m}^{2}$ & & $\mathrm{Rp}$ & $1,343,481,753.14$ \\
\hline \hline
\end{tabular}

\section{PERBANDINGAN BIAYA MATERIAL}

Perbandingan biaya, semua struktur mempunyai biaya yang jauh berbeda. Penggantian pelat lantai beton dengan pelat lantai pracetak ringan dan bata merah dengan bata ringan jelas mempunyai pengaruh terhadap struktur terutama pada dimensi, volume beton, volume tulangan dan pondasi tiang pancang dari sebuah bangunan. Struktur eksisting, struktur modifikasi 1, struktur modifikasi 2 mempunyai selisih biaya yang cukup besar.
Selisih biaya antara struktur eksisting dengan struktur modifikasi 1, adalah sebesar $12.70 \%$ yaitu Rp 925,923,369.61 dan selisih biaya antara struktur eksisting dengan struktur modifikasi 2 adalah sebesar $18.36 \%$ yaitu $\mathrm{Rp}$ $1,338,149,665.30$. Selisih biaya tersebut bisa direduksi dengan penggunaan pelat lantai pracetak ringan dengan beton aerasi dan bata ringan dengan beton aerasi.

\section{PENUTUP}

\section{A. Kesimpulan}

Berdasarkan hasil perhitungan yang dilakukan, maka dapat disimpulkan beberapa hal sebagai berikut:

1) Alternatif penggunaan pelat lantai pracetak ringan dan bata ringan sangat mempengaruhi struktur terutama pada beban yang diterima struktur yang secara langsung mempengaruhi volume sebuah struktur dan dapat dilihat dari perbandingan biaya yang sangat signifikan antara struktur eksisting, 
struktur modifikasi 1, dan struktur modifikasi 2 .

2) Penurunan biaya antara struktur eksisting dengan struktur modifikasi 1, adalah sebesar $12.70 \%$ yaitu $\mathrm{Rp}$ 925,923,369.61 dan penurunan biaya antara struktur eksisting dengan struktur modifikasi 2 adalah sebesar $18.36 \%$ yaitu Rp 1,338,149,665.30

\section{B. Saran}

Penelitian yang dilakukan pada bentuk gedung yang reguler, disarankan untuk penelitian selanjutnya dilakukan pada bentuk gedung yang irregular dan juga menambahkan perbandingan waktu sehingga dapat diketahui perbandingan waktu dan biayanya.

\section{DAFTAR PUSTAKA}

[1] Pramono Setiabudi Prabowo Analisis Hambatan dan Peluang Penggunaan Bata dan Beton Ringan AAC pada Proyek Gedung dan Perumahan di Surabaya

[2] Toreh R Y R 2012 Perbandingan Penggunaan Material Konvensional dengan Beton Ringan pada Proyek Gedung Teknik Elektro ITS

[3] Narayanan V K 2000 Structure and Properties of Aerated Concrete 